\title{
A unique case of electric circular saw suicide with injuries to the chest and abdomen
}

\author{
Paul Bedford
}

Victorian Institute of Forensic medicine

Southbank, Victoria, Australia

\begin{abstract}
This case report discusses the previously unreported situation of a suicidal death, with injuries to the chest, by means of an electric circular saw. A review of the English and German literature provides an overview of common sites of injury, gender and psychiatric status in power saw related deaths.
\end{abstract}

Keywords:

Suicide, Electric circular saw

\section{INTRODUCTION}

Suicidal deaths utilising electrical power saws are exceedingly rare with 20 cases having been reported in the English and German literature [1-13]. Furthermore the use of electric circular saws is a subset of this group with only 6 cases identified. This case is unique in that a circular saw has been used to inflict fatal injuries upon the chest and abdomen. Exsanguination has resulted primarily from injuries to the heart and the liver. The case findings are documented and a review of the literature is provided. A table is produced which includes gender, the type of power saw and the site of the injuries.

\section{CASE REPORT}

A 45 year old man was found lying on his back with a pillow under his head. Next to him attached to an extension lead, plugged into the laundry, was an electric Makita circular saw (Example- Figure 1). A suicide note was present in the kitchen. The post mortem examination revealed three

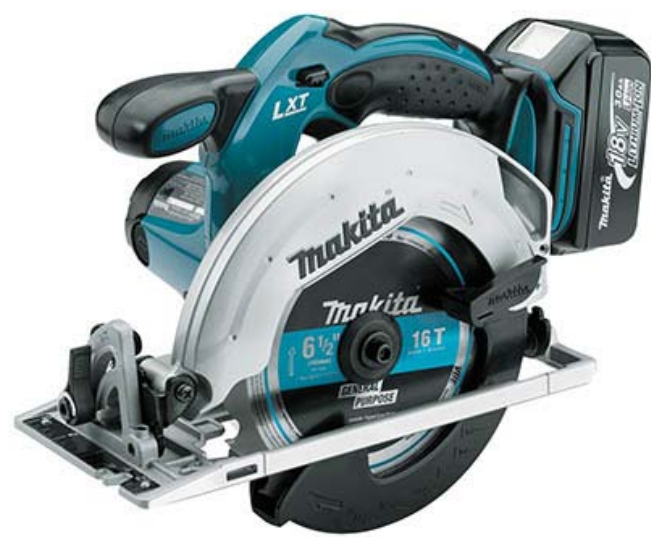

Figure 1. Example of a Makita circular saw. largely horizontally oriented incised lesions aggregating in a central focus over the lower chest and upper central abdomen (Figure 2). These varied in length from 21 to $25 \mathrm{~cm}$ and resulted in a lesion affecting the pericardium, with a $9 \mathrm{~cm}$ right ventricular lesion as well as injuries to the mediastinum, diaphragm, stomach, ribs and liver. Three lesions in the liver varied in length from 5 to $17 \mathrm{~cm}$. There were bilateral hemothoraces with one liter of blood in each cavity. No signs of previous self harm such as cuts on the wrists were present. Toxicology studies were negative except for a low level of the drug mirtazapine which is used in the treatment of depression. The cause of death was listed as exsanguination from circular saw incised injuries to the chest and abdomen.

\section{DISCUSSION}

This is the only identified case in the English and German literature where a suicidal death has been caused by the use of an electric circular saw to inflict injuries to the chest and abdomen (see Table 1). The literature shows that nearly all suicides with power operated saws involve either the head or

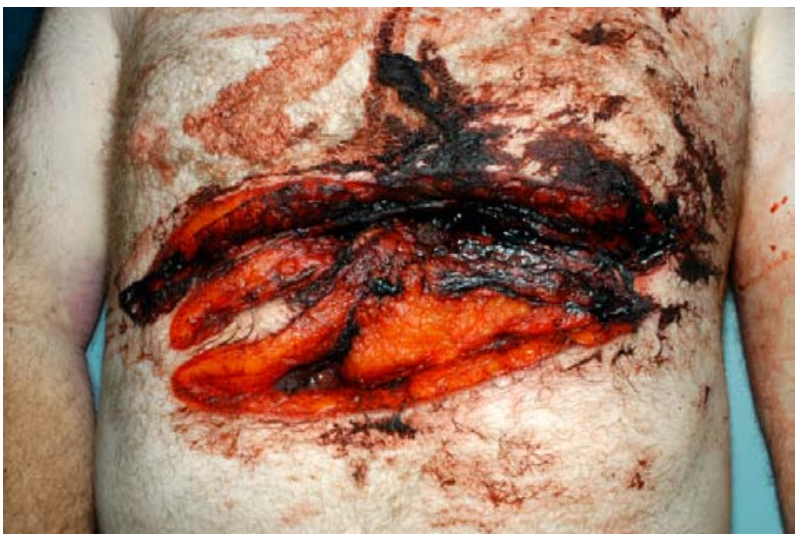

Figure 2. Lower chest and abdominal injuries. 
Table 1. The table documents age, gender, type of power saw, the site of injuries and whether there was a history of psychiatric illness.

\begin{tabular}{|c|c|c|c|c|c|}
\hline Author & Age & Sex & Type of Saw & Main injury site & Psychiatric Illness \\
\hline Betz & 33 & $\mathrm{~F}$ & Circular Saw & Neck & Yes \\
\hline Betz & 45 & $\mathrm{~F}$ & Circular Saw & Left Arm & Yes \\
\hline Grellner & 29 & $\mathrm{~F}$ & Circular Saw & Neck & Yes \\
\hline Judd & 47 & $M$ & Circular Saw & Head & Yes \\
\hline Asano & 32 & $\mathrm{~F}$ & Circular Saw & Neck & Yes \\
\hline Dolenc & 44 & $M$ & Circular Saw & Head & Yes \\
\hline Reuhl & 31 & $M$ & Chain Saw & Neck & Yes \\
\hline Tournel & 32 & $\mathrm{~F}$ & Chain Saw & Neck & Yes \\
\hline Segerberg-Kontinnen & 54 & M & Chain Saw & Chest & Yes \\
\hline Grellner & 30 & $\mathrm{~F}$ & Chain Saw & Neck & Yes \\
\hline Campman & 69 & M & Chain Saw & Neck & Yes \\
\hline Campman & 27 & $M$ & Chain Saw & Neck & Yes \\
\hline Schiwy-Bochat & 19 & M & Chain Saw & Head & Yes \\
\hline Betz & 54 & $M$ & Band Saw & Head & Not stated \\
\hline Betz & 48 & $\mathrm{~F}$ & Band Saw & Head & Yes \\
\hline Clark & 37 & $M$ & Band Saw & Neck & Yes \\
\hline Gloulou & 41 & M & Band Saw & Neck & Yes \\
\hline Gloulou & 47 & M & Band Saw & Head & Yes \\
\hline Härtel & 34 & $M$ & Band Saw & Head & Yes \\
\hline Härtel & 41 & $M$ & Band Saw & Neck & Yes \\
\hline
\end{tabular}

the neck. One case of injury to the arms is noted [1]. Another case involved a knife injury to the chest followed by the use of a chain saw to the chest resulting in a pneumothorax and exsanguination but no injury to the heart or other internal organs [4]. Generally powered saw suicides have shown a predominance of male victims. With circular saw related deaths there is a different pattern with a greater number of female deaths. It is noted that the numbers are however quite low. As is in this case there is, as expected, a background of psychiatric disease, with a previous diagnosis of depression and the use of mirtazapine.

With any unexpected, unusual trauma related death, consideration should always be given to whether or not the events relate to a homicide. In this case the event appears to have been planned taking place in an unobstructed area in the garden behind the house, with a suicide note, use of an extension cord, and the placing of a pillow under the head.

\section{CONCLUSION}

This case appears to be unique where a suicidal death has resulted from severe injuries to the chest and abdomen by utilising an electric circular saw. The majority of cases in the literature describe powered saw deaths involving injuries to the head and neck.

\section{REFERENCES}

[1] Betz P., Eisenmenger W., Unusual suicides with electric saws, Forensic Sci Int.,1995, Oct 30;75(2-3):173-9

[2] Judd O., Wyatt JP., Circular saw suicide, J Forensic Leg Med., 2007, May;14(4):2357., Epub 2007, Feb 22

[3] Gloulou F., Allouche M., Khelil MB., Bekir O., Banasr A., Zhioua M., et al., Unusual suicides with band saws: Two case reports and a literature review, Forensic Sci Int., 2009, Jan 10;183(1-3):e7-10. Epub 2008, Nov 18. Review
[4] Segerberg-Konttinen M., Suicide by the use of a chain saw, J Forensic Sci., 1984, Oct;29(4):1249-52

[5] Asano M., Nushida H., Nagasaki Y., Ueno Y., Suicide by a circular saw, Forensic Sci Int., 2008, Nov 20;182(1-3):e7-9. Epub 2008 Nov 5

[6] Campman SC., Springer FA., Henrikson DM., The chain saw: an uncommon means of committing suicide, J Forensic Sci., 2000, Mar;45(2):471-3 
[7] Grellner W., Wilske J., Unusual suicides of young women with tentative cuts and fatal neck injuries by chain saw and circular saw, Forensic Sci Int., 2009, Sep 10;190(13):e9-11. Epub 2009 Jun 21

[8] Reuhl J., Bratzke H., Death caused by a chain saw- homicide, suicide or accident? A case report with a literature review (with 11 illustrations), Forensic Sci Int., 1999, Oct25;105(1):45-59. Review

[9] Tournel G., Dedouit F., Balgairies A., Houssaye C., De Angeli B., Becart-Robert A, et al., Unusual suicide with a chainsaw, J Forensic Sci., 2008;53(5):1174-7
[10] Clark S.P., Delahunt B., Thomson K.J., Fernando T.L., Suicide by band saw, Am. J.Forensic Med. Pathol., 10 (1989), 332-334

[11] Schiwy-Bochat K.H., Wound pattern in fatal suicidal chain saw injury, Rechtsmedizin2 (1992), 71-73

[12] Härtel V., Petkovits T., Brinkmann B., Unusual suicides with band saws, Arch. Kriminol. 184 (1989), 168-174

[13] Dolenc A., and Lovsin J., Eigenartige Selbstmordfälle, Beitr. gerichtl. Med., 37 (1979), 235-240 